ORIGINAL ARTICLE

\title{
Perception of exercise induced asthma by children and their parents
}

\section{S Panditi, M Silverman}

Arch Dis Child 2003;88:807-811

See end of article for authors' affiliations .....................

Correspondence to: Professor M Silverman, Department of Child Health \& Institute for Lung Health, University of Leicester, Robert Kilpatrick Clinical Sciences Building, Leicester Royal Infirmary, PO Box 65, Leicester LE2 7LX, UK; ms70@le.ac.uk

Accepted

30 December 2002
Background: Exercise induced asthma (EIA) plays an important role in clinical evaluation. There has been little previous work validating EIA as reported directly by children and indirectly by their parents. Aims: (1) To determine the strength of the association between children's symptoms of EIA and their physiological response to exercise in a laboratory setting. (2) To compare parents' perception of EIA with that of their children. (3) To seek factors influencing the perception of EIA.

Methods: Forty three asthmatic children and their parents answered a questionnaire, which included measures of symptom perception in EIA using visual analogue (VAS) and Likert scales. The children underwent a standardised treadmill exercise challenge, using spirometry to measure the physiological outcome, after which they and their parents independently completed the symptom scores. Twenty four subjects agreed to return for a second visit, in order to assess repeatability.

Results: The VAS and Likert scales were highly correlated. Children's symptom perception as measured by change in VAS scores related weakly to change in FEV, after exercise, and was unaffected by confounding factors such as age, gender, medication, and habitual exercise. Parents' perception of symptoms was unrelated to any physiological measure. There was no significant relation between parent and child VAS scores after exercise, and there was poor agreement between the Likert scale scores after exercise. The repeatability of the perception of change in FEV after exercise was poor for both parents and children.

Conclusion: Physicians should obtain reports of EIA from children rather than parents, but be aware of their limited accuracy and repeatability.
$\mathrm{E}$ xercise induced asthma (EIA) is the "transient narrowing of the airways that follows vigorous exercise". ${ }^{1}$ It is reported to occur in up to $80 \%$ of asthmatics, most frequently in children and young adults, due perhaps to their higher levels of physical activity. ${ }^{2}$ EIA can be disabling, resulting in exclusion or withdrawal from physical activity. ${ }^{3}$

In laboratory studies, EIA represents the airways' responses to the stimulus of hyperventilation, mediated by drying (or cooling) of the inflamed bronchial epithelium. ${ }^{12}$ Under standardised conditions EIA is an index of bronchial hyperresponsiveness in asthma. ${ }^{56}$

In clinical practice, the report of EIA by children with asthma plays a central role in management. It enables health professionals to assess the severity or level of control of disease and the disability experienced. It is thus used, overtly or tacitly as a surrogate measure of bronchial hyperresponsiveness, without a formal challenge test. The perception of airway obstruction in asthma is dependent not only on the degree and site of airway narrowing, ${ }^{78}$ but also on the modulating effects of inflammation, ${ }^{9}{ }^{10}$ drug therapy, ${ }^{11-15}$ and the prevailing severity of airway obstruction ${ }^{16}{ }^{17}$ (as implied by Weber's Law).$^{18}$ In addition, psychological influences include: prior experiences (hence developmental "norms"), beliefs, higher order processing, and, in the case of children, parental influences. ${ }^{8}$

Parental perception of children's asthma is secondary. Parents of younger children perceive changes in forced expiratory volume in one second $\left(\mathrm{FEV}_{1}\right)$ and peak expiratory flow (PEF) more accurately than their children, whereas the converse is true for parents of older children. ${ }^{19}$ Parents of children with moderate morbidity are more accurate perceivers than those of children with severe morbidity. ${ }^{20}$ There are thus differences in parental and child perception of measured airway obstruction and of symptoms.
Considering its importance in clinical practice, there have been few studies evaluating the child's perception of EIA. While breathlessness caused by exercise (not EIA, which was not induced in this study) is well perceived, ${ }^{21}$ one study found no links between "dyspnoea" and change in $\mathrm{FEV}_{1}$ in very mild EIA. ${ }^{17}$ In the one study which has reported the perception of EIA in children and their parents, ${ }^{22}$ children and parents were not asked the same questions and parents were not present at the time of the exercise challenge, so perceptual data were not acquired simultaneously.

The present study aimed: (1) to determine the strength of the relation between symptoms of EIA reported by children and their physiological response to exercise in a laboratory setting; (2) to compare parents' independent perception of EIA with that of their child; and (3) to seek the factors influencing the perception of the physiological response to exercise.

\section{SUBJECTS AND METHODS}

The study took place at the Children's Asthma Centre, Leicester Royal Infirmary, UK. Forty six children and their parents were recruited; 14 were from an asthma clinic and 32 from local general practices. The children were aged 7-14 years of age, had a clinical diagnosis of asthma, were taking some form of regular medication, and had had no severe exacerbations or changes to their preventer therapy in the four weeks prior to the test. Twenty four subjects volunteered to return for a second identical set of tests (within eight weeks of the first), which enabled repeatability to be tested.

Abbreviations: BTS, British Thoracic Society; EIA, exercise induced asthma; FEF, forced expiratory flow; $F_{E V}$, forced expiratory volume in one second; FVC, forced vital capacity; PEF, peak expiratory flow; VAS, visual analogue scale 
Both parents and children gave written informed consent. The study was approved by the Leicestershire Research Ethics Committee.

\section{Measurement of perception}

A $10 \mathrm{~cm}$ visual analogue scale (VAS) was constructed with "very bad" and "no problem at all" marked at the extremities. Children or parents were separately asked "Can you mark on the line how your (your child's) asthma was last week when you (your child) did exercise?". In order to determine the perception of asthma severity immediately before and after the exercise challenge test, the question "Can you mark on the line how your (your child's) asthma is now?" was used. The questions and end points were non-specific, in that they did not enquire about a particular symptom or sensation of EIA, as interpretation might depend on the child's understanding or knowledge. The authors based the questions on pilot work to investigate the terminology used by children.

Perception was also measured on a five point categorical (Likert) scale, to determine the level of "bother" (again, not symptom specific) associated with EIA. The questions were exactly the same for both children and parents: "How bothered were you (was your child) by asthma after the running test?"- - extremely bothered, bothered a lot, bothered a bit, hardly bothered at all, not bothered. This question was only asked after exercise.

The following potential confounders of the association between perception and physiological response to exercise were recorded prior to the exercise challenge: age, gender, asthma severity (by British Thoracic Society (BTS) step ${ }^{23}$ ), medication, habitual exercise, attitude towards exercise, and competitiveness. Attitude towards exercise was derived from a validated questionnaire ${ }^{24}$ using the question "I think that doing exercise long enough to get sweaty a few times a week, during my free time is: (i) very good fun, fairly good fun, neither good fun nor unpleasant, fairly unpleasant, or very unpleasant; (ii) very unhealthy, fairly unhealthy, neither healthy nor unhealthy, fairly unhealthy, or very unhealthy".

Level of habitual exercise was assessed by asking parents/ children to identify which activities were done over the past week, and their frequency, duration, and intensity. An intense activity was one that raised the heart rate and caused sweating. The majority of children did a large number of activities, so categorisation by frequency and time was not possible. Categorisation by intensity included three categories: no intense activity, some intense activity, and all intense activity. Parents and children who attended the laboratory completed the questionnaire and each of the perception scales separately, without collusion at any stage.

\section{Exercise challenge}

The exercise challenge was a six minute run on a treadmill (Quinton Q50, USA) at a speed of $6-8 \mathrm{~km} / \mathrm{h}$, and a gradient of $8-10 \%$ to achieve a heart rate of $85 \%$ of the maximum predicted value [220 - age (y)], by the end of the exercise period. The laboratory was air conditioned $\left(19-21^{\circ} \mathrm{C}\right.$; relative humidity $<50 \%$ ) during all exercise tests. Measurements of lung function, including PEF, and several spirometric indices were made from full forced vital capacity (FVC) manoeuvres using an electronic spirometer (Vitalograph Compact Spirometer, Ireland), calibrated before the arrival of each subject using a 2 litre syringe (Jaeger). Lung function was measured before (best of three blows according to ATS criteria ${ }^{25}$ ) and at $1,3,5,10,20$, and 30 minutes after completing exercise (single blows). The FVC manoeuvres were carried out with the child sitting and with a nose clip. Neither the child nor parents saw the spirometry results. The level/severity of EIA was expressed as the maximum change after exercise from the baseline value of lung function (\%). Children whose FEV fell by $13 \%$ or more were classified as having exercise induced asthma. $^{5}$
Following the test, after each set of forced vital capacity manoeuvres children were asked: "Describe in your own words how you are feeling now", to capture qualitatively their perception of symptoms.

Once the $\mathrm{FEV}_{1}$ had returned to within 5\% of baseline, parents and children completed the VAS and Likert scales for a final time. If a child's FEV 1 had not returned to within about $5 \%$ of baseline by 30 minutes, $400 \mu \mathrm{g}$ of salbutamol was administered by metered dose inhaler and spacer.

\section{Statistical methods}

At least 14 subjects were required, in order to have $80 \%$ power to detect a true correlation between perceptual score and physiological measures of EIA of 0.7. However, the confidence intervals are wide ( 0.3 to 0.85$)$. Thus 40 subjects were selected as the sample number to allow for defective data.

Absolute VAS scores were log transformed to achieve normality, as there was positive skewing towards the "no problem at all" end. The change in VAS after exercise was not normally distributed, and so we used the change in log VAS score after exercise, which was normally distributed.

Separately for children and parents, linear regression analysis was used to compare the change in log VAS scores with the change in lung function after exercise. Absolute log VAS scores after exercise were also compared to change in lung function. The absolute log VAS scores for EIA perceived in the previous week were also compared to the severity of EIA in the laboratory.

Parent and child VAS scores before and after exercise as well as change in VAS on exercise were compared by linear regression. Kappa was used to compare parents' and children's categorical scale scores. The effect of confounding factors was to be analysed by multiple regression. To evaluate repeatability in symptom perception, differences in the change in log VAS scores between the first and second visit were regressed against differences in the change in lung function.

To validate the VAS, the absolute VAS score after exercise for both parents and children was compared to the categorical scale by linear regression. Repeatability was assessed using the technique of Bland and Altman. Analysis was done with SPSS version 10 .

\section{RESULTS}

Forty six children were recruited; results from only 43 were analysed, as two children were not on regular medication and one had extremely variable spirometry results, which made interpretation difficult. Thirty six completed the exercise test satisfactorily on the first visit; three children ran for under six minutes because of severe bronchoconstriction, and four could not achieve target heart rate but were still included for analysis as they appeared to be exerting maximum effort while running. On the second visit all 24 children completed the exercise test satisfactorily. The first and repeat visit groups did not differ in age, baseline $\mathrm{FEV}_{1}$, or features of asthma (table 1). Overall, $60 \%$ developed EIA on test 1 and $63 \%$ on test 2 . The mean fall in $\mathrm{FEV}_{1}$ after exercise was $22 \%$ and $21 \%$ respectively.

\section{Visual analogue scale}

Using the VAS, children's perception was related weakly to change in $\mathrm{FEV}_{1}$ after exercise $\left(r^{2}=0.1, \mathrm{p}=0.04\right.$; fig 1$)$, but not to change in PEF, $\mathrm{FEF}_{50}$, or $\mathrm{FEF}_{25-75}$. Reported severity of EIA (by VAS) over the previous week was unrelated to any measure of EIA.

Parents' perception, measured either by change in log VAS scores $\left(r^{2}=0.03 ; \mathrm{p}=0.28\right)$ or by absolute log VAS $\left(r^{2}=0.06\right.$; $\mathrm{p}=0.09$ ) after exercise, was unrelated to any measure of EIA, as was parents' reports of their child's EIA over the previous week.

Parents' VAS related poorly to child's VAS before $\left(r^{2}=0.002\right.$; $\mathrm{p}=0.78)$ and after exercise $\left(r^{2}=0.06 ; \mathrm{p}=0.12\right)$. Furthermore, change in parent VAS score related poorly to change in child VAS score after exercise $\left(r^{2}=0.03 ; \mathrm{p}=0.28\right)$. 


\begin{tabular}{|c|c|c|}
\hline Subject characteristics & $\begin{array}{l}\text { Single visit } \\
(n=19)\end{array}$ & $\begin{array}{l}\text { Repeat visits } \\
(n=24)\end{array}$ \\
\hline Boys/girls (n) & $13 / 6$ & $18 / 6$ \\
\hline Age (y) & $7-13$ & $9-14$ \\
\hline Eczema/hayfever (\%) & $42 / 53$ & $58 / 50$ \\
\hline \multicolumn{3}{|l|}{ BTS step (\%) } \\
\hline Step 2 & 63 & 79 \\
\hline Step $3+4$ & 26 & 21 \\
\hline Not known & 11 & \\
\hline \multicolumn{3}{|c|}{ Baseline lung function $(\% \text { predicted })^{33}$} \\
\hline FEV & $87.2(10.9)$ & $83.5(10.0)$ \\
\hline PEF & $85.6(17.0)$ & $85.4(12.2)$ \\
\hline $\mathrm{FEF}_{25-75}$ & $66.7(20.8)$ & $65.7(18.8)$ \\
\hline $\mathrm{FEF}_{50}$ & $73.2(22.3)$ & $70.6(17.9)$ \\
\hline Exercise induced asthma (n) & 11 & 15 \\
\hline \multicolumn{3}{|l|}{ Habitual level of exercise (\%) } \\
\hline No intense activity & 5 & \\
\hline Some intense activity & 79 & 62 \\
\hline All intense activity & 16 & 38 \\
\hline Competitive exercise (\%) & 53 & 67 \\
\hline
\end{tabular}

Results expressed as number or mean (SD).

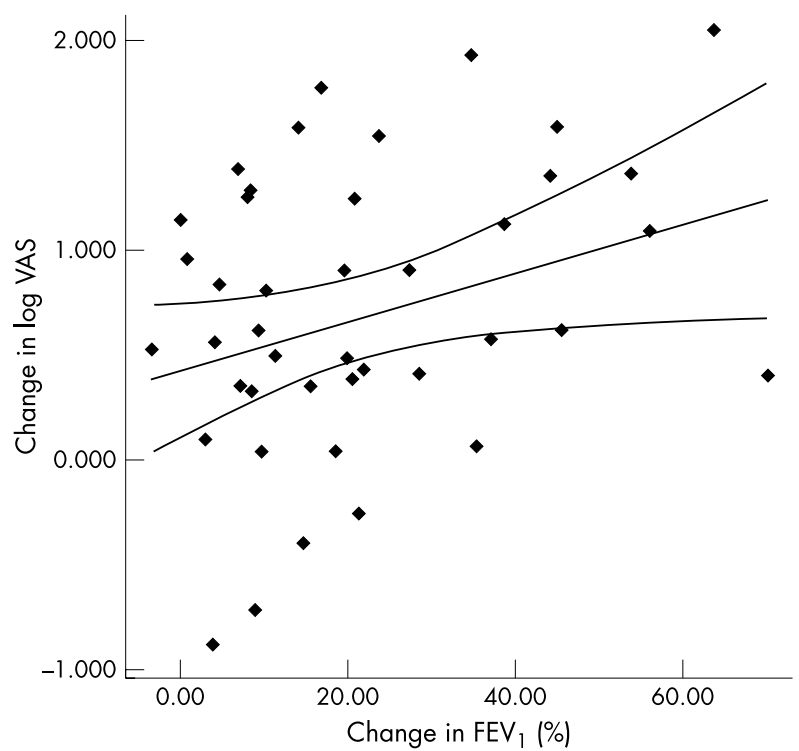

Figure 1 Child's change in log of VAS and change in $\mathrm{FEV}_{1}$ after exercise challenge, showing regression line and its $95 \%$ confidence interval.

\section{Likert (bother) scales}

There was very poor agreement between parents' and children's categorical "bother" scores $(\kappa=0.095)$.

However, the "bother" and VAS sores were highly correlated for children $\left(r^{2}=0.50 ; \mathrm{p}<0.001\right.$; fig 2$)$, and for parents $\left(r^{2}=0.58, \mathrm{p}<0.0001\right)$. There was a poor relation between the "bother" scale and EIA or lung function. For children who had marked "not bothered" and parents who marked "bothered a bit" the mean fall in $\mathrm{FEV}_{1}$ was $46 \%$.

\section{Qualitative descriptors}

Children's free descriptors recorded at five minutes after exercise (the time point of minimum mean $\mathrm{FEV}_{1}$, when shortness of breath caused by exercise had abated), fell into two categories: symptoms specific for asthma (tight chest, wheeze, breathlessness, and cough); and non-specific symptoms (such as "out of breath", headache, leg ache, etc). The specificity and sensitivity of any asthma specific symptom for EIA (fall in $\mathrm{FEV}_{1} \geqslant 13 \%$ ) were $82 \%$ and $50 \%$ respectively.

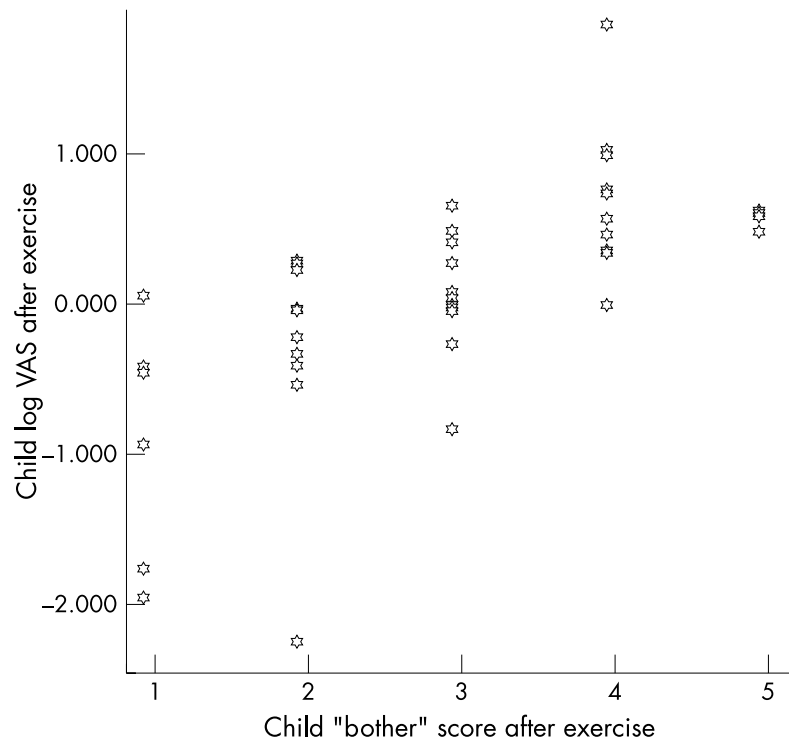

Figure 2 Child's log VAS score compared to categorical scale ("bother scale") after exercise.

\section{Confounders}

None of the potential confounding factors (age, gender, asthma severity, medication, habitual exercise, attitude, and competitiveness) showed any association with the children's perceptual scores $(p=0.2-0.9)$. Multiple regression analysis was therefore not carried out.

\section{Repeatability}

Both for parents and children there were great discrepancies between repeat visits, with no significant overall relation between the change in log VAS and the change in severity of EIA between visits. However, for 20/24 children the changes in VAS score and EIA were in the same direction, although 13 of these children had small differences in both. The other four children had large differences in EIA between visits, but with paradoxical changes in VAS. In one example, on visit 1 , change in $\mathrm{FEV}_{1}$ was $8 \%$ and change in log VAS was 2.3 , and on visit 2 , change in $\mathrm{FEV}_{1}$ was $19 \%$, but change in log VAS was only 0.9 . These four children reported more habitual exercise than the rest of the group, but had a neutral attitude to whether exercise was healthy or fun.

\section{DISCUSSION}

This study aimed to assess the validity of a report by asthmatic children and their parents, of the severity of the child's EIA. It showed that children's reports of EIA following a standardised exercise test in a laboratory, relate weakly to objective measures of severity (change in $\mathrm{FEV}_{1}$ ) after exercise. Children's retrospective reports of EIA over the previous week, the kind of information which is often used in clinical management, bore no relation to the laboratory measurements. Parents' perception of their child's EIA, measured in the laboratory by two different scales, did not relate to any lung function measurements.

Children's perception of EIA was not affected by any of several potential confounding factors such as age, gender, asthma severity, medication, and habitual exercise. Most of the descriptive comments made five minutes after stopping exercise (when the breathlessness of exercise had subsided and EIA was at its maximum) were unrelated to EIA. The poor outcome was not explained by the cross sectional nature of the study, since in the longitudinal part of the study, both children and parents were inconsistent in their ability to perceive symptoms on repeat visits. 


\section{Methodological issues}

The two main outcome measures are the physiological measurements and the perceptual scales. FEV $\mathrm{V}_{1}$ as determined by spirometry was used as a measure of EIA. $\mathrm{FEF}_{25-75}$ and $\mathrm{FEF}_{50}$ were also measured in an attempt to identify children who may perceive changes in their small airways, but with even poorer statistical associations. Change in $\mathrm{FEV}_{1}$ was perceived more accurately than change in PEF. Spirometry itself, as a result of forced vital capacity ("big breath") manoeuvres, may affect airway function for up to two minutes. This is a potential problem with all such studies. In no case was there an obvious deterioration or improvement in $\mathrm{FEV}_{1}$ within sets of repeated blows. We consider that a big breath effect was unlikely to explain the discrepancy between perception and physiology.

Exercise testing was standardised, although for the purposes of the study, this was not strictly necessary, since a wide variation of EIA was sought (and expected), both between subjects and within subjects for repeat measurements.

The VAS designed for this study was non-specific and the questions used simple terminology. The scale was well understood by children, and in fact parents had more difficulty in using the scale. Studies using specific scales have shown mixed results. Ergood and colleagues ${ }^{21}$ used a VAS to assess breathlessness on exercise (but not EIA), and found it correlated well with physiological measures. However, Baker and colleagues, ${ }^{26}$ who measured the perception of bronchoconstriction in children after methacholine challenge with a specific breathlessness scale found that there was a poor relation with physiological measures.

The marking of a VAS can be distorted by habitual trends and patterns by individual subjects. In this study there was positive skewing towards the "no problem" end, as previously reported by others. ${ }^{27}$ Individuals tend to be consistent in under- or over-rating scales. This could explain the good correlation between VAS and categorical scales. To control for this, an independent VAS enquiring about for example the perception of pain when pricked by pin, would have been helpful. However, the categorical scale was derived (for comparison) from a questionnaire previously validated by Juniper and colleagues ${ }^{28}$; the VAS thus appeared to be a valid measure of perception, although neither scale correlated with physiological measures.

The study size was adequate to give a power of $80 \%$ to detect a clinically useful correlation (0.7) between perceptual score and physiological measures of EIA. However, there was a degree of self selection bias, which accounts for the uneven distribution of subject characteristics. Older children were targeted without success. Previous studies using older children have found an effect of age. ${ }^{19}{ }^{20}$ The sample also had a high proportion of mild asthma (BTS step 2), which may explain why no effect of either treatment or asthma severity was found. It was expected that children with severe asthma would have blunted perception (as has previously been shown, ${ }^{16}$ and would be expected by a simple application of Weber's Law), but there were small numbers of children on BTS steps 3 and 4 medication. There was no effect of habitual level of exercise, attitude towards exercise, or competitiveness, which were expected to alter "norms" and hence the perception of EIA. Other confounders such as emotional state, intelligence, health beliefs, and level of bronchial hyperresponsiveness before visiting the laboratory may have altered symptom perception, but were not measured. ${ }^{8}$ These were, of course irrelevant in the longitudinal component of the study.

\section{Clinical implications}

This study has highlighted some important clinical issues. Health professionals need to be aware that reports of EIA may not be reliable and that children may be describing symptoms other than those of EIA. This was illustrated by the modest specificity $(82 \%)$ and low sensitivity $(50 \%)$ of children's descriptions. The effect of potential confounding factors on the perception of EIA should be considered, although we failed to show their importance in this study. Parental perception of EIA was poor, and this suggests that a child's history is more accurate. The results of this study are consistent with those of Lara and colleagues, ${ }^{22}$ who found child's perception related to change in large airway obstruction (FEV, was not measured) on exercise, whereas parents' perception did not.

Parents and children were inconsistent in their ability to perceive symptoms during repeat visits. Four of 24 children reported paradoxical changes in symptoms. If true, this has major clinical implications. The physician relies on the child and parent to be accurate and consistent at each visit in order, for example, to make decisions about the control of asthma and to modify therapy. Wilson and colleagues ${ }^{29}$ showed the VAS to have poor repeatability in a time period of 2-6 weeks, but our categorical "bother" scale was equally poor. Studies in adults have shown that by using bronchial hyperresponsiveness (by methacholine challenge) as a clinical outcome target, improvements in asthma outcome can be achieved. ${ }^{30}$ In children a history of EIA as a surrogate measure of bronchial hyperresponsiveness for clinical management, although widely used, appears to be less reliable. Regular lung function measurements provide an alternative, but may be no better. ${ }^{31}$ New techniques to target airway inflammation could be more appropriate, although they will be difficult to apply to children. ${ }^{32}$

\section{Further research}

This study has provided some foundations for future research in this area. A step forward would involve distinguishing the level of breathlessness caused by exercise from that caused by airway obstruction; for example, on the one hand by preventing the bronchoconstriction of exercise by prior administration of a bronchodilator, and on the other by inducing airway obstruction (say, with methacholine) without exercise. There may also be a need for more qualitative research in this area, in which children describe their symptoms in terms familiar to themselves rather than by the use of scales (albeit nonspecific). ${ }^{34}$ Such an approach might identify more discriminating terms to describe EIA. ${ }^{35}$ Finally, further information on confounding factors is required. This research would allow for further understanding of children's concepts and illness beliefs associated with EIA and hence strengthen the value of the question "What happens to your asthma when you run around?"

\section{ACKNOWLEDGEMENTS}

We would like to thank Dawn Jotham and Lisa Pidgeon for their technical help, Dr Diane Wensley for advice on many issues, and Professor John Thompson for statistical help. Dr Len Almond, Loughborough University, advised on the measurement of daily exercise. We thank the parents and children who participated in this study. Finally, we are grateful to the PPP Foundation for their financial support.

Authors' affiliations

S Panditi, M Silverman, Department of Child Health \& Institute for Lung Health, University of Leicester, UK

\section{REFERENCES}

1 Anderson SD, Daviskas E. The mechanism of exercise-induced asthma is... J Allergy Clin Immunol 2000;106:453-9.

2 Makker AC, Holgate ST. Mechanisms of exercise-induced asthma. Eur J Clin Invest 1994;24:571-85.

3 Godfrey S. Exercise-induced asthma. In: Barnes PJ, Grunstein MM, Leff AR, Woolcock AJ, eds. Asthma. Philadelphia: Lippincott-Raven, 1997:1 105-19.

4 Mead D. Asthma, children and physical exercise. Nursing Standard 1990;4:28-31. 
5 Godfrey S, Springer C, Bar-Yishay, et al. Cut-off points defining normal and asthmatic reactivity to exercise and inhalation challenges in children and young adults. Eur Respir J 1999;14:659-68.

6 Van Schoor J, Joos GF, Pauwels RA. Indirect bronchial

hyperresponsiveness in asthma: mechanisms, pharmacology and implications for clinical research. Eur Respir J 2000;16:514-33.

7 McFadden ER, Kiser R, de Groot WJ. Acute bronchial asthma. N Engl J Med 1973;288:221-5.

8 Rietveld S, Prins PRJ. Children's perception of physical symptoms: the example of asthma. In: Ollendick TH, Prinz RJ, eds. Advances in clinical child psychology, Vol 20. New York: Plenum Press, 1998:153-82.

9 Burdon JGW, Juniper EF, Killian KJ, et al. The perception of breathlessness in asthma. Am Rev Respir Dis 1982;1 26:825-8.

10 Boner AL, De Stefano G, Piacentini GL. Perception of bronchoconstriction in chronic asthma. J Asthma 1992;29:323-30.

11 Wilson JD, Sutherland DC, Thomas AC. Has the change to beta-agonists combined with oral theophylline increased cases of fatal asthma? Lancet $1981 ; 1: 1235-7$

12 Otanelli R, Rosi E, Romagnoli I. Do inhaled corticosteroids affect perception of dyspnoea during bronchoconstriction in asthma? Chest 2001; 120:770-7.

13 Salome CM, Reddel HK, Ware IW. Effect of budesonide on the perception of induced airway narrowing in subjects with asthma. Am J Crit Care Med 2002;165:15-21.

14 van Schayck CP, Biil-Hofland ID, Cloosterman SGM, et al. Potentia masking effect on dyspnoea perception by short- and long-acting $\beta_{2}$-agonists in asthma. Eur Respir J 2002;19:240-5.

15 Jang AS, Choi IS. Increased perception of dyspnea by inhalation of short acting $\beta_{2}$ agonist in patients with asthma of varying severity. Ann Allergy Asthma Immunol 2000;84:79-83.

16 Male I, Richter H, Seddon P. Children's perception of breathlessness in acute asthma. Arch Dis Child 2000;83:325-9.

17 Rietveld S, Prins PJM. Accuracy of symptom perception in asthma and illness severity. Child Health Care 2001:30:27-41.

18 Fritz GK, McQuaid EL, Nassau JH, et al. Thresholds of resistive load detection in children with asthma. Pediatr Pulmonol 1999:28:271-6.

19 Guyatt GH, Juniper EF, Griffith LE, et al. Children and adult perceptions of childhood asthma. Pediatrics 1997;99:165-8.

20 Yoos HL, McMullen A. Symptom perception and evaluation in childhood asthma. Nurs Res 1999:48:2-8.
21 Ergood JS, Epstein LH, Ackerman M, et al. Perception of expiratory flow by asthmatics and non-asthmatics during rest and exercise. Health Psychol 1985;4:545-54.

22 Lara M, Duan N, Sherbourne C, et al. Differences between child and parent reports of symptoms among Latino children with asthma. Pediatrics 1998; 102:e68.

23 British Thoracic Society, et al. The British guidelines on asthma management: 1995 review and position statement. Thorax 1997;52(suppl 1).

24 Godin G, Shephard RJ. Psychosocial factors influencing intentions to exercise of young students from grades 7 to 9. Res Q Exerc Sport 1986;57:41-52.

25 American Thoracic Society. Standardisation of spirometry: 1994 update. Am J Respir Crit Care Med 1995;152:1107-36.

26 Baker RR, Mishoe SC, Zaitoun FH, et al. Poor perception of airway obstruction in children with asthma. J Asthma 2000;37:613-24.

27 Fritz GK, Klein RB, Overholser JC. Accuracy of symptom perception in childhood asthma. Dev Behav Pediatr 1990;1 1:69-72.

28 Juniper EF, Guyat GH, Feeny DH, et al. Measuring quality of life in children with asthma. Qual Life Res 1995;5:35-46.

29 Wilson RC, Jones PW. A comparison of the visual analogue scale and modified Borg scale for the measurement of dyspnoea during exercise. Clin Sci 1989:76:277-82

30 Sont JK, Willems LNA, Bel EH, et al. Clinical control and histopathologic outcome of asthma when using airway hyperresponsiveness as an additional guide to long-term treatment. Am J Respir Crit Care Med. 1999;159:1043-51.

31 Wensley $D$, Silverman $M$. The use of peak flow monitoring in guided self management of childhood asthma: a randomised controlled trial. Am J Respir Crit Care Med. Submitted.

32 Green R, Brightling C, McKenna S, et al. Reduced asthma exacerbations with a management strategy directed at normalising the sputum eosinophil count. A randomised comparison with traditional management. Lancet 2002;360:1715-21.

33 Polgar G, Promadhat V. Pulmonary function testing in children: techniques and standards. London: WB Saunders Company, 1971.

34 Young B, Fitch GE, Dixon-Woods M, et al. Parents' accounts of wheeze and asthma related symptoms: a qualitative study. Arch Dis Child 2002;87:131-4.

35 Killian KJ, Watson R, Otis J, et al. Symptom perception during acute bronchoconstriction. Am J Respir Crit Care Med 2000;162:490-6.

\section{ARCHIVIST}

\section{Kindergarten-based outbreak of perianal group A streptococcal infection}

$\mathrm{P}$ erianal cellulitis due to group A beta-haemolytic streptococcal infection (PASI) was first reported in 1966. Children are affected much more frequently than adults, and boys more than girls. There is usually a well demarcated perianal rash, often with pain, pruritus, and blood streaked stools but no fever or other systemic symptoms. Relatively little is known about the epidemiology of this disease. Danish workers (Jesper P Petersen and colleagues. Pediatric Infectious Disease Journal 2003;22:105-9) have reported what they claim is the largest documented outbreak so far.

Cases of perianal erythema and bloody stools were noticed in a kindergarten in a rural community in Denmark beginning in November 1999. The first cases were misdiagnosed as pinworms or thrush but after the diagnosis of PASI was made in one child local practitioners were informed of the diagnosis and advised to take perianal and throat swabs from subsequent cases. Over a 4-month period 17 children had PASI. Twelve of these ( 11 boys) had an apparently identical strain of group A beta-haemolytic streptococcus (T type 28 and identical profiles on pulsed field gel electrophoresis) grown from perianal swabs. Six of these 12 children attended the kindergarten, four were household contacts of kindergarten children or staff, and only two had no known connection. During the same period five people with PASI (one adult) were infected with different strains of the organism giving an estimated background (non-outbreak) annual incidence of 2-7 per 1000 children. Initially treatment with oral penicillin $\mathrm{V}$ failed in three children but all children responded to oral clarithromycin.

This outbreak was apparently caused by a single clone of group A beta-haemolytic streptococcus. Treatment with clarithromycin was effective. The infection may be more common than has been realised. 